\title{
Correction to: Maternal Hypertension, Advanced Doppler Haemodynamics and Therapeutic Precision: Principles and Illustrative Cases
}

\author{
Rob A. Phillips ${ }^{1} \cdot$ Z. $\mathrm{Ma}^{2} \cdot$ B. Kong ${ }^{2} \cdot$ L. Gao ${ }^{2}$ \\ Published online: 24 August 2020 \\ (C) Springer Science+Business Media, LLC, part of Springer Nature 2020
}

Correction to: Current Hypertension Reports (2020) 22: 49 https://doi.org/10.1007/s11906-020-01060-2

The original publication of this article, unfortunately, contains the following errors.

1. P7 - line 8; "Apgar score at 1 min of 9" should read "Apgar score at $1 \mathrm{~min}$ of 5"

2. P7 - "Human and Animal Rights and Informed Consent This article does not contain any studies with human or animal subjects performed by any of the authors."

Should read

"Human and Animal Rights and Informed Consent Examinations were acquired following patient informed consent, as part of routine pre-operative clinical assessment by qualified and accredited medical practitioners using noninvasive and clinically proven technologies. Data were not used to change patient management and were included in this presentation following patient approval and data deidentification."

Publisher's Note Springer Nature remains neutral with regard to jurisdictional claims in published maps and institutional affiliations.

The online version of the original article can be found at https://doi.org/ 10.1007/s1 1906-020-01060-2

Rob A. Phillips

r.phillips1@uq.edu.au

1 The Critical Care Research Group, Department of Medicine, The University of Queensland, Brisbane, Australia

2 Department of Maternal Intensive Care Medicine Unit, Shandong Maternal and Child Health Hospital, Jinan, Shandong, China 